\title{
Genetic evidence for sex-specific migratory behaviour in western South Pacific humpback whales
}

\author{
Elena Valsecchi ${ }^{1, *}$, Peter J. Corkeron ${ }^{2}$, Paolo Galli $^{1}$, William Sherwin ${ }^{3}$, \\ Giorgio Bertorelle ${ }^{4}$
}

\begin{abstract}
${ }^{1}$ Department of Biotechnology and Biosciences, University of Milano-Bicocca, Piazza della Scienza 2, 20126 Milan, Italy ${ }^{2}$ Bioacoustics Research Program, Cornell Lab of Ornithology, 159 Sapsucker Woods Road, Ithaca, New York 14850, USA

${ }^{3}$ School of Biological, Earth and Environmental Sciences, University of New South Wales, Sydney, NSW 2052, Australia ${ }^{4}$ Department of Biology, University of Ferrara, Via L. Borsari, 46, 44100 Ferrara, Italy
\end{abstract}

\begin{abstract}
Although predictable in its areas of occurrence, many aspects of humpback whale migration are still poorly understood. Nuclear DNA analysis has revealed a low level of relatedness among whales using the same migratory corridor, and has shown that closely related individuals tend not to travel in spatial association. Yet it still remains uncertain whether whales from different matrilineally discrete feeding stocks travel along the same migratory corridor for later mixing in common breeding waters. The western and central South Pacific Ocean is the only ocean basin where thousands of islands and reefs occur as suitable wintering habitat for humpback whales, so here their migratory behaviour may not be constrained by habitat. We analysed sex-specific and temporal distributions of 42 mitochondrial haplotypes detected in 135 humpback whales sampled off eastern Australia throughout 1 annual migration. A noticeable difference was found in haplotypic composition between northbound males and females, suggesting that the 2 sexes of any single matrilineal stock might select different and only partially overlapping migratory routes. We hypothesise that males most closely related to the N-S migrating females off eastern Australia migrate north elsewhere, perhaps past New Zealand. These findings suggest that longitudinal movements by male humpback whales are probably more extensive than currently thought, and indicate the need for reexamination of genetic data from humpback whales in the South Pacific, disaggregated by gender.
\end{abstract}

KEY WORDS: Cetacea $\cdot$ Control region $\cdot$ GAMOVA $\cdot$ Breeding grounds $\cdot$ mtDNA

\section{INTRODUCTION}

Movements of marine megafauna pose ecological questions at ocean basin scales. Migrations of baleen whales are spectacular annual events in some coastal marine systems. The humpback whale Megaptera novaeangliae (Borowski 1781) is the most intensely studied baleen species. It occurs in all the world oceans, summering in high-latitude feeding grounds, and wintering in tropical, typically coastal, calving and breeding grounds. Aspects of their migration, including the selective pressures driving it, remain contentious (e.g. Mehta et al. 2007, Rasmussen et al. 2007, Ford \& Reeves 2008).
Most knowledge of humpback whale biology comes from studies on summering and wintering grounds (Clapham 2000), although some features of the species' migratory behaviour are fairly clear. The migratory flow is temporally clustered, with the timing of movements of adult females regulated by their reproductive state (Chittleborough 1965, Dawbin 1966). The migratory timing of individual females differs according to reproductive state, and appears to influence reproductive success (Craig et al. 2003). In some populations, males comprise the majority of migrating animals (Brown et al. 1995, Craig \& Herman 1997), indicating that females do not migrate every year. Analyses of nuclear DNA variation in migrating ani- 
mals indicate that whales do not migrate in kin-based social units (Valsecchi et al. 2002, Pomilla \& Rosenbaum 2006).

Access to suitable sites for calving and/or mating appears to constrain the migratory destinations of humpback whales in most ocean basins. Most breeding areas are approximately $20^{\circ}$ from the equator (Clapham \& Mead 1999), and exceptions to this suggest that access to relatively warm, calm water is a prerequisite for successful breeding (Rasmussen et al. 2007). In the North Atlantic for example, whales from all known summering areas migrate to one wintering area, the Caribbean, (although some also migrate to the Cape Verde Islands; Jann et al. 2003). Whales from the Barents Sea, that must make the longest migration to the Caribbean, appear less likely to migrate than others (Stevick et al. 2003). In the eastern South Pacific, humpback whales that summer in Antarctic waters migrate across the equator to wintering grounds in Central America (Rasmussen et al. 2007), apparently in response to a lack of suitable southern breeding habitat.

The western and central South Pacific Ocean is the only ocean basin where thousands of islands and reefs occur at approximately $20^{\circ}$ latitude. This creates a band of suitable wintering habitat for humpback whales (Garrigue et al. 2000) across approximately $70^{\circ}$ of longitude, so migratory behaviour should not be constrained by habitat. Results of 'Discovery' tagging in the 1950s and early 1960s (Chittleborough 1965, Dawbin 1966), supplemented by recent photo-identification studies (Garrigue et al. 2000, 2007a,b), have demonstrated interchange of animals between eastern Australia, New Zealand, New Caledonia, Tonga, the Cook Islands and French Polynesia.

Most interchanges were observed between years, but 4 occurred within 1 migration. One, a female 'Discovery' tagged in Cook Strait New Zealand in June 1960, was killed off Moreton Island, eastern Australia, 20 d later (Chittleborough 1961). In 1999, a whale, recorded as possibly male (Garrigue et al. 2007a, Table $3)$, moved from the Cook Islands to Tonga. In 2004, 2 males (out of a total of 13 whales photographically identified) swimming north off New Zealand were reidentified on the southward migration off eastern Australia (Garrigue et al. 2007b, Table 3). Humpback whales seem to learn the route to their feeding grounds from their mother during their first migration (Clapham 2000, Rendell \& Whitehead 2001). This results in matrilineally organised fidelity to feeding areas, best revealed by studies of matrilineal (mtDNA) genetic markers (e.g. Larsen et al. 1996). In the southwest Pacific however, the extent to which whales from different feeding stocks intermix at low latitudes is unclear. While re-sighting (e.g. Garrigue et al. 2000, 2007a,b) and genetic tagging (Pomilla \& Rosenbaum
2006) records across adjacent breeding grounds and the infiltration of male song between western and eastern Australian migratory corridors (Noad et al. 2000) suggests the (perhaps occasional) sharing of migratory routes by different feeding stocks, this might not be the case for all breeding destinations.

From a study based on both molecular and photoidentification records collected over a period of $7 \mathrm{yr}$ from over 200 individuals sampled in the waters of New Caledonia, Garrigue et al. (2004) conclude that humpback whales wintering off New Caledonia constitute an isolated breeding population. This was debated by Palsbøll et al. (2005) who argued that the results observed by Garrigue et al. (2004) are also compatible with a scenario in which males from adjacent breeding populations (e.g. eastern Australia) were mating with New Caledonian females. Baker et al. (2005) responded that the results of Garrigue et al. (2004) are not compatible with the possibility of temporary immigration of eastern Australian males given the most recent estimates of the migratory population off eastern Australia (Paterson et al. 2001).

This debate appears to include a common assumption of the migratory behaviour of humpback whales: although male whales occasionally undertake longer longitudinal movements than females, the general pattern of the migration stream of both sexes is similar, even when females appear not to migrate each year. But selective pressures on males and females are different. Males, seeking to maximize mating opportunities, should be more likely to make longitudinal movements than females, as females need to minimise the energetic costs of migration. Tagging and photoidentification data suggest that in the western South Pacific, male humpbacks may be more likely to make within-migration longitudinal movements than females (Garrigue et al. 2007a,b).

Photo-identification data have recently been used to suggest the possibility of a migratory linkage between New Zealand and eastern Australia (Franklin et al. 2008). Preliminary analysis of photo-identification data for 1543 identified individuals at 3 sites off the eastern Australian coast over a 7 yr period demonstrated low within-year re-sighting rates $(3.5 \%$, Gibson et al. 2009). However, available data are insufficient to distinguish between occasional movements by individuals (of either gender), and different migratory behaviour by males and females from distinct feeding areas.

Another way of testing the possibility of the common use of the same migratory corridor by 2 or more feeding stocks would be to study the composition of the population of migrants sampled during their travel over the whole period of the migratory flow (rather than at the breeding ground of destination where it would be hard to estimate time and route of arrival). 
The temporal segregation demonstrated in humpback whale migration, coupled with the presence of discrete feeding stocks, might lead to an uneven distribution of haplotypes during the migration.

Here we study the mtDNA distribution of 135 humpback whales sampled while migrating off eastern Australia during a complete (north- and south-bound) annual migration. Both features (sampling before/after reaching breeding ground latitudes and throughout a single year's migration) make this sample set unique. Our aims were to test whether the humpback whales migrating off eastern Australia (1) constitute a homogeneous population and (2) whether (and if so, to what extent) they intermix with whales from adjacent breeding grounds, from which molecular data are now available (Olavarría et al. 2007).

\section{MATERIALS AND METHODS}

Mitochondrial DNA analysis of a portion of the control region was performed on 135 individual humpback whales, sampled in 1992 throughout their annual migration off eastern Australia (off Stradbroke Island, Queensland). These individuals include a sub-sample of the whales previously analysed at the nDNA level by Valsecchi et al. 2002. Here we integrated also singletons or whales which were the only sampled member in pods of 2 or more individuals: these individuals, for the purpose of the research, were excluded in the previous study (Valsecchi et al. 2002). The current sample set included 44 females and 91 males, the skewed sex-ratio being due to the predominance of males among humpback whales migrating in this region (Brown et al. 1995). Duplicated samples from the same individual, as well as calves and yearlings sampled in the company of their mothers (see Valsecchi et al. 2002), were excluded from the current sample.

Both migratory phases were represented: 58 individuals were sampled during the northward migration (towards the breeding grounds), and 77 individuals were sampled during the southward migration (towards the feeding grounds). The samples were collected from 71 pods. For $42(59.2 \%)$ of the pods, 2 to 5 (mean 2.5) individuals were analysed. For the remaining 29 pods, only 1 pod-member was typed. Analysed individuals were sampled over a total of $38 \mathrm{~d}$, evenly spread over a 4 mo period from 5 June to 21 October 1993, during which biopsies were collected (Brown et al. 1995, Valsecchi et al. 2002). The number of typed individuals sampled on 1 single day ranged from 1 to 11 (mean = 3.6). Further details on the sample collection, sex determination and temporal distribution can be found in previous papers (Brown \& Corkeron 1995, Brown et al. 1995, Valsecchi et al. 2002).
Sequencing reactions were performed on a $\sim 540 \mathrm{bp}$ PCR-product amplified using primers DLP-5 (Baker et al. 1993) and Mt15996L (Campbell et al. 1995). Haplotypes were sequenced using the BigDye (Applied Biosystems) terminator cycle-sequencing kit and run on an ABI377 automated sequencer (Applied Biosystems).

Levels of mtDNA polymorphism within the sample set were measured by estimating both haplotype $(\mathrm{H})$ and nucleotide $(\pi)$ diversities (Nei 1987), computed using the software package ARLEQUIN 3.11 (Excoffier et al. 2005).

The distribution of mitochondrial haplotypes within the 1992 humpback whale migration was analysed by testing the null hypothesis that whales migrating off the eastern Australian coastline constitute, at least within the same breeding season, a single population. If such a hypothesis is met, we would expect homogeneity between migrant whales regardless of whether or not they are split into different sex/migratory classes. Therefore we performed a range of tests among classes of individuals identified according to the sex and/or migratory phase (i.e. northbound from 6 June 1993 to 14 August 1993, or southbound from 21 August 1993 to 20 October 1993). All 3 possible comparisons (males versus females, northern versus southern migrations and their interaction, i.e. northern-males versus northern-females versus southern-males versus southern-females) were analysed using $\Phi_{\mathrm{ST}}$ as a measurement of genetic distance based on pairwise differences, computed using ARLEQUIN 3.11 (Excoffier et al. 2005).

In order to assess the extent to which the 2 different factors (sex and migratory direction) affected levels of genetic difference between the various sample subclasses, we also used the generalised AMOVA (GAMOVA) approach (Nievergelt et al. 2007). Unlike the AMOVA analysis (Excoffier et al. 1992) this method is not based on a hierarchical analysis, but rather on a multiple conditional regression approach. This has the advantage of being able to detect the influence of different predictor variables on the pattern of genetic variation without selecting in advance their hierarchical structure.

Our sequences were then aligned and compared with data from Olavarría et al. (2007), who analysed mtDNA variation in 1112 whales (115 haplotypes) sampled from 5 South Pacific breeding grounds (New Caledonia, Tonga, Cook Islands, French Polynesia and Colombia), as well as 1 from the Southern Indian Ocean (western Australia). These sample sets were collected over approximately a decade: 1990 to 2002. Our complete data set and subsets of it were compared with these data in order to estimate whether, and to what extent, whales from adjacent 
breeding areas might use the eastern Australian migratory corridor. Consistently with the first part of our analysis, we used $\Phi_{\mathrm{ST}}$ as index of genetic divergence and the generalised analysis of molecular variance (GAMOVA).

\section{RESULTS}

Sequencing analysis of $371 \mathrm{bp}$ of the mtDNA control region of 135 eastern Australian humpback whales identified 47 variable sites (Table 1). These included

Table 1. Megaptera novaeangliae. Sequence variation and sex-specific distribution of 42 mtDNA haplotypes (371 bp) detected in 135 humpback whales sampled off eastern Australia in 1992. The first column represents the haplotypes and their frequencies (in brackets). The 47 variable sites (positions indicated by the vertical numbers, between 44 and 368, at the top of the table) are shown in the central part of the table. (.) = identity at the corresponding position in haplotype H01. (-) = 1 base pair deletion. Complete sequences are available from GenBank (Accession numbers AF419261-AF419271, GQ872082- GQ872112). 'Clade' and 'Equal to' columns refer to, respectively, sequence typology (see text) and haplotype identity with reference to Olavarría et al. (2007). The sex-ratios (males:females) of individuals carrying each specific haplotype are shown for the overall sample set (all) and for animals sampled during the northern $(\mathrm{N})$ or the southern $(\mathrm{S})$ migration

\begin{tabular}{|c|c|c|c|c|c|c|}
\hline & \multirow{2}{*}{ 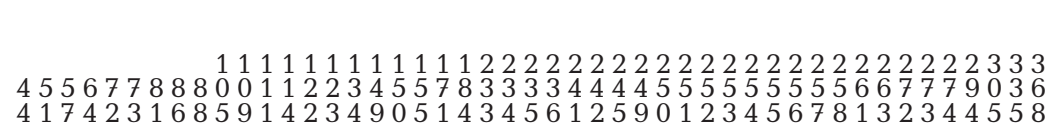 } & \multirow{2}{*}{$\begin{array}{l}\mathrm{C} \\
\mathrm{l} \\
\mathrm{a} \\
\mathrm{d} \\
\mathrm{e}\end{array}$} & \multirow[b]{2}{*}{ Equal to } & \multicolumn{3}{|c|}{$\begin{array}{c}\text { Sex ratio } \\
(\mathrm{M}: \mathrm{F})\end{array}$} \\
\hline & & & & All & $\mathrm{N}$ & $\mathrm{S}$ \\
\hline H01 (10) & GTCTTTGTCG - CTAGTTCCCTGCCCAATAGGCTCATCTGCTCTATTC & $\mathrm{CD}$ & SP71 & $4: 6$ & $0: 3$ & $4: 3$ \\
\hline H02 (3) & $\ldots \ldots$. & $\mathrm{CD}$ & SP73 & $0: 3$ & 0:0 & $0: 3$ \\
\hline H03 (1) & $\ldots \ldots \ldots \ldots \ldots . \ldots$. & $\mathrm{CD}$ & SP76 & $1: 0$ & 0:0 & $1: 0$ \\
\hline $\mathrm{H} 40$ (1) & $\ldots \ldots \ldots \ldots \ldots$ & $\mathrm{CD}$ & SP77 & 1:0 & $0: 0$ & $1: 0$ \\
\hline H04 (1) & 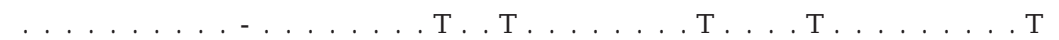 & $\mathrm{CD}$ & SP78 & $1: 0$ & $1: 0$ & 0:0 \\
\hline H05 (2) & $\ldots \mathrm{C} \ldots \mathrm{T}$. $\ldots \mathrm{T} \ldots \mathrm{T} \ldots \ldots$ & $\mathrm{CD}$ & SP68,SP70 & $0: 2$ & $0: 0$ & $0: 2$ \\
\hline H06 (3) & 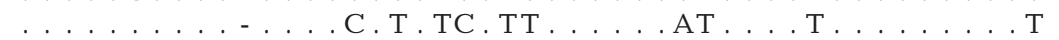 & $\mathrm{CD}$ & SP64,SP65,SP66 & $3: 0$ & $2: 0$ & $1: 0$ \\
\hline $\mathrm{H} 07$ (9) & 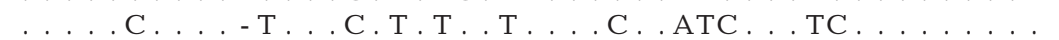 & $\mathrm{CD}$ & SP63 & $7: 2$ & 1 & $1: 1$ \\
\hline H08 (1) & $\ldots$. . . . . . . T. T. T. & $\mathrm{CD}$ & & $1: 0$ & 0 & $: 0$ \\
\hline H09 (4) & $\ldots$. . . . . . ....... & $\mathrm{CD}$ & SP87 & $3: 1$ & 1 & $2: 0$ \\
\hline H10 (2) & $\ldots$. . . A. . . C.. T & $\mathrm{CD}$ & $\mathrm{SP}$ & $1: 1$ & 0 & $0: 1$ \\
\hline H11 (4) & $\ldots$. . . . . . . . & $\mathrm{CD}$ & $\mathrm{SP}$ & $2: 2$ & 2 & $1: 0$ \\
\hline $\mathrm{H} 12$ (4) & $\ldots \mathrm{T}, \mathrm{T} \ldots \mathrm{T} \ldots \mathrm{G} \ldots$ & $\mathrm{CD}$ & SP91 & $2: 2$ & $1: 2$ & $1: 0$ \\
\hline H13 (6) & $\mathrm{T} \ldots \mathrm{T} \ldots \mathrm{T} \ldots \mathrm{C} \cdot \mathrm{CC}$ & $\mathrm{CD}$ & SP85 & $3: 3$ & $2: 1$ & $1: 2$ \\
\hline $\mathrm{H} 14$ (5) & $\ldots$. . . . . . & $\mathrm{CD}$ & SP1,SP113 & $4: 1$ & $2: 0$ & $2: 1$ \\
\hline H37 (1) & $\ldots \mathrm{C}$ А . АС Т ТА . & $\mathrm{CD}$ & SP108 & $1: 0$ & $0: 0$ & $1: 0$ \\
\hline H41 (1) & 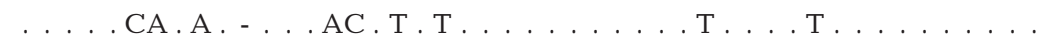 & $\mathrm{CD}$ & SP114 & $0: 1$ & $0: 0$ & $0: 1$ \\
\hline H42 (1) & $\ldots$. . . . . AC.T.T & $\mathrm{CD}$ & & $1: 0$ & $0: 0$ & $1: 0$ \\
\hline H15 (4) & $\ldots$. . . T. . AC . T. T & $\mathrm{CD}$ & SP102 & $2: 2$ & $0: 1$ & $2: 1$ \\
\hline H16 (1) & Т.... . . . . . . . . & $\mathrm{CD}$ & SP104 & $1: 0$ & $0: 0$ & $1: 0$ \\
\hline H17 (7) & $\ldots$. . . . Т. A..... & $\mathrm{CD}$ & SP96 & $3: 4$ & $1: 2$ & $2: 2$ \\
\hline H38 (1) & $\ldots \mathrm{T} \ldots \ldots \mathrm{T}, \mathrm{T} \ldots \mathrm{T} \ldots \ldots$ & $\mathrm{CD}$ & SP99 & $0: 1$ & $0: 0$ & $0: 1$ \\
\hline H18 (4) & $\ldots \ldots$.... TCT . T. A . . . . & $\mathrm{CD}$ & SP55 & $3: 1$ & $1: 0$ & $2: 1$ \\
\hline H19 (1) & $\ldots \ldots$. . . ТСТ . . . . СG . & $\mathrm{CD}$ & SP52 & $0: 1$ & $0: 0$ & $0: 1$ \\
\hline H20 (1) & $\ldots \ldots$. . . . . . . . . & $\mathrm{CD}$ & SP54 & 1:0 & $0: 0$ & 1:0 \\
\hline H21 (8) & 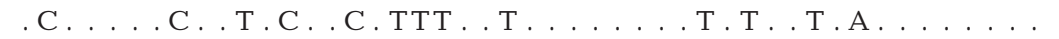 & IJ & SP10 & $7: 1$ & $5: 0$ & $2: 1$ \\
\hline H22 (6) & .C.... C..T.C. . C. TTT. & IJ & SP26 & $5: 1$ & 1:0 & $4: 1$ \\
\hline H23 (2) & 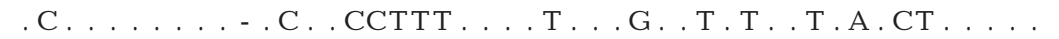 & IJ & SP27 & $2: 0$ & 1:0 & $1: 0$ \\
\hline H39 (1) & 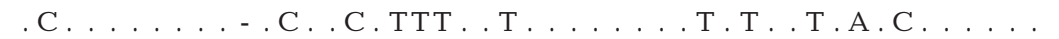 & IJ & SP25 & $1: 0$ & 0:0 & $1: 0$ \\
\hline $\mathrm{H} 24$ (1) & . C. . . . C. . . . . . . TTT. & IJ & SP19,SP20 & $1: 0$ & 1:0 & $0: 0$ \\
\hline $\mathrm{H} 25$ (7) & . C.... . . T.C. . С. TTT. & IJ & SP14,SP15 & $5: 2$ & 1:0 & $4: 2$ \\
\hline H26 (1) &. C.... . . T. . . . TTT & IJ & & $0: 1$ & $0: 0$ & $0: 1$ \\
\hline H27 (7) &. C....C..T.C. . C. TTT. & IJ & SP13 & $7: 0$ & $5: 0$ & $2: 0$ \\
\hline H28 (1) & 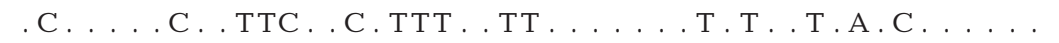 & IJ & & $1: 0$ & $0: 0$ & $1: 0$ \\
\hline H29 (5) & 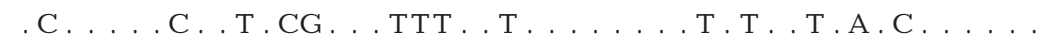 & IJ & SP11 & $5: 0$ & $3: 0$ & $2: 0$ \\
\hline H30 (1) & $. \mathrm{T} \ldots \ldots \mathrm{T} . \mathrm{T} \ldots \mathrm{T} . \mathrm{A} \ldots \ldots \mathrm{C}$ & IJ & SP42 & 1:0 & 1:0 & $0: 0$ \\
\hline H31 (3) & 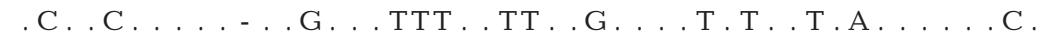 & IJ & SP46 & $2: 1$ & $2: 1$ & $0: 0$ \\
\hline H32 (2) & 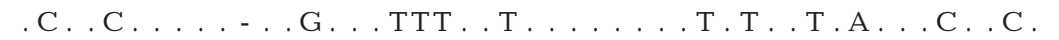 & IJ & SP41 & $2: 0$ & $0: 0$ & $2: 0$ \\
\hline H33 (4) & . . ......... . TTT. & IJ & SP49 & $2: 2$ & 1:0 & $1: 2$ \\
\hline H34 (1) & . . .......... . TTT. & IJ & SP37 & 1:0 & 0:0 & 1:0 \\
\hline H35 (1) & 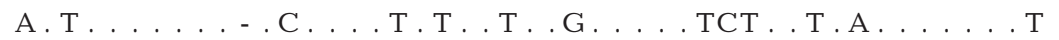 & $\mathrm{SH}$ & & $1: 0$ & $1: 0$ & $0: 0$ \\
\hline \multirow[t]{2}{*}{ H36 (6) } & 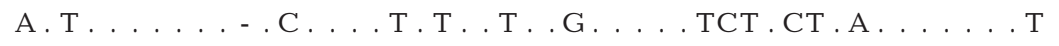 & $\mathrm{SH}$ & SP3 & $3: 3$ & $1: 2$ & $2: 1$ \\
\hline & & & Totals & 91:44 & $42: 16$ & $49: 28$ \\
\hline
\end{tabular}


45 transitions (including 1 instance of an individual presenting a deletion at position 114), 1 transitiontransversion (position 88) and 1 insertion-deletion (position 109), identifying 42 different haplotypes (Table 1). The insertion in position 109 was observed in 8 different haplotypes and 36 individuals $(26.7 \%)$. Seventeen haplotypes $(40.5 \%)$ were carried by 1 individual only, while the remaining 25 haplotypes (59.5\%) were carried by 2 to 10 (mean 4.76) individuals. The estimated haplotype $(\mathrm{H})$ and nucleotide $(\pi)$ diversities for the total sample were 0.968 and 0.026 respectively. Values of the same estimates calculated for the various sex and migration population subclasses are shown in Table 2 .

Most haplotypes ( $\mathrm{n}=40,95.2 \%)$ and individuals ( $\mathrm{n}=$ $128,94.8 \%$ ) could be placed into 2 (CD and IJ) of the 3 primary clades (CD, IJ and $\mathrm{AE}$ ) described by Baker et al. $(1993,1998)$ for humpback whales worldwide. The CD clade was the most represented, being found in 78 individuals $(57.8 \%)$ and 25 haplotypes $(59.5 \%)$. The IJ clade was encountered in 50 individuals (37\%) and 15 haplotypes $(35.7 \%)$. Seven whales $(5.2 \%)$ carried 2 haplotypes (H35 and H36) clustering in the $\mathrm{SH}$ clade, more recently described by Olavarría et al. (2007). No animal clustered in the AE clade, which characterises almost exclusively North Pacific individuals (e.g. Baker et al. 1993, 1998). Most ( $\mathrm{n}=$ $37,88.1 \%$ ) of the 42 haplotypes detected in this study were identical to those found in other areas of the South Pacific and off western Australia (Olavarría et al. 2007; see also Table 1).

The results of multiple tests for population subdivision based on sex and migratory phase are shown in Table 3. The distance-based estimator $\Phi_{\mathrm{ST}}$ revealed highly significant $(p=0.001)$ differences between the 2 sexes, but not between migration phases $(p=$ 0.492). When sex classes were further subdivided according to the migration phase in which individuals were sampled and the 4 sub-classes $(\mathrm{NM}=$ northbound males, $\mathrm{SM}=$ southbound males, NF = northbound females, $\mathrm{SF}=$ southbound females) were reciprocally compared, the estimator for population differentiation revealed a significant difference between northbound males and northbound females $(\mathrm{p}=0.001$, see
Table 3). Although not significant after the correction for multiple tests (but with p-values $<0.02$ ), the second and third highest levels of genetic differentiation were recorded between males and females travelling in opposite directions (i.e. NM versus SF and SM versus $\mathrm{NF}$ ). The significant influence of the predictor variable 'sex' in determining the pattern of genetic variation is supported also by the generalised analysis of molecular variance (GAMOVA). In fact, the conditional $F$ statistics provided for this variable are highly significant (Table 4, Analysis 1).

Position 1 of the 371 bp fragment analysed in this study corresponded to position 12 in the $470 \mathrm{bp}$ region sequenced by Olavarría et al. (2007). Considering our $371 \mathrm{bp}$ (373 bp if the indel sites of position 117 and 131

Table 2. Megaptera novaeangliae. Haplotype $(\mathrm{H})$ and percentage of nucleotide $(\pi)$ diversities in the whole and sub-classes of the sample set. Corresponding values, relative to the homologous $373 \mathrm{bp}$-fragment, found in the adjacent breeding grounds are shown for comparisons (data retrieved from Olavarría et al. 2007). Numbers of individuals and of haplotypes are indicated by $n$ and $n_{h}$ respectively. The column on the right-hand side shows the number of individuals in each of the 4 clades (AE,CD, IJ and $\mathrm{SH}$ ) described in previous studies (Baker et al. 1993, 1998, Olavarría et al. 2007)

\begin{tabular}{|lccccc|}
\hline Sample & $\mathrm{n}$ & $\mathrm{n}_{\mathrm{h}}$ & $\mathrm{H}(\mathrm{SD})$ & $\% \pi(\mathrm{SD})$ & AE/CD/IJ/SH \\
\hline EA all & 135 & 42 & $0.968(0.004)$ & $2.61(1.33)$ & $0 / 78 / 50 / 7$ \\
$\quad$ EA males & 91 & 36 & $0.968(0.006)$ & $2.56(1.31)$ & $0 / 45 / 42 / 4$ \\
EA females & 44 & 23 & $0.961(0.013)$ & $2.51(1.31)$ & $0 / 33 / 8 / 3$ \\
EA north & 58 & 25 & $0.959(0.010)$ & $2.74(1.41)$ & $0 / 32 / 22 / 4$ \\
EA south & 77 & 37 & $0.972(0.007)$ & $2.51(1.29)$ & $0 / 46 / 28 / 3$ \\
EA males north & 42 & 23 & $0.951(0.017)$ & $2.61(1.35)$ & $0 / 19 / 21 / 2$ \\
EA females north & 16 & 10 & $0.942(0.036)$ & $2.60(1.41)$ & $0 / 13 / 1 / 2$ \\
EA males south & 49 & 30 & $0.976(0.009)$ & $2.52(1.31)$ & $0 / 26 / 21 / 2$ \\
EA females south & 28 & 19 & $0.971(0.016)$ & $2.47(1.30)$ & $0 / 20 / 7 / 1$ \\
WA & 174 & 53 & $0.966(0.005)$ & $2.49(1.27)$ & $0 / 105 / 66 / 3$ \\
NC & 250 & 61 & $0.972(0.003)$ & $2.54(1.29)$ & $0 / 149 / 85 / 16$ \\
TG & 310 & 48 & $0.962(0.004)$ & $2.46(1.26)$ & $0 / 196 / 99 / 15$ \\
CI & 131 & 23 & $0.923(0.010)$ & $2.39(1.23)$ & $0 / 85 / 44 / 2$ \\
FP & 99 & 21 & $0.913(0.012)$ & $2.32(1.20)$ & $0 / 63 / 29 / 7$ \\
Col & 148 & 27 & $0.900(0.016)$ & $2.26(1.17)$ & $3 / 98 / 47 / 0$ \\
\hline
\end{tabular}

Table 3. Megaptera novaeangliae. Estimates of genetic differentiation $\left(\Phi_{\mathrm{ST}}\right)$ obtained in pairwise comparisons between sexes and/or migratory classes $(\mathrm{M}=$ males, $\mathrm{F}=$ females, $\mathrm{N}=$ northbound whales, $\mathrm{S}=$ southbound whales). Significance levels are estimated from 10000 permutations; $p$-values are shown $(\mathrm{p}<0.05)$ after correction for multiple comparison with the sequential Bonferroni test (Rice 1989)

\begin{tabular}{|lccrc|}
\hline Comparison between & Categories & Sizes & \multicolumn{1}{c|}{$\Phi_{\mathrm{ST}}$} & $\mathrm{p}$ \\
\hline Sexes & M vs F & 91 vs 44 & 0.053 & $\mathbf{0 . 0 0 1}$ \\
Migrations & N vs S & 58 vs 77 & -0.002 & 0.492 \\
Sexes within migrations & NM vs NF & 42 vs 16 & 0.114 & $\mathbf{0 . 0 0 1}$ \\
& SM vs SF & 49 vs 28 & 0.008 & 0.215 \\
Sexes between migrations & NM vs SF & 42 vs 28 & 0.055 & 0.011 \\
& SM vs NF & 49 vs 16 & 0.062 & 0.016 \\
Migrations within sex & NM vs SM & 42 vs 49 & 0.001 & 0.357 \\
& NF vs SF & 16 vs 28 & -0.005 & 0.512 \\
\hline
\end{tabular}


Table 4. Megaptera novaeangliae. GAMOVA analysis estimates of the proportion of variation in individual mtDNA sequences explained by 2 factors, sex and the migration direction, in the eastern Australia samples (Analysis 1), and by 7 different Southern Ocean breeding grounds (Analysis 2). Pseudo-F $=$ the statistic measuring the influence of the different variables on individual genetic background similarities, PVE = the proportion of variation in the genetic background similarity matrix explained by the variable (sex, migration or population), Cum PVE = the cumulative proportion of variation explained by the variable, $\mathrm{p}=$ the probability associated with the pseudo- $F$ based on 10000 data permutations

\begin{tabular}{|c|c|c|c|c|}
\hline Predictor variable & Pseudo- $F$ & PVE & Cum PVE & $\mathrm{p}$ \\
\hline \multicolumn{5}{|c|}{$\begin{array}{l}\text { Analysis 1: the influence of sex and migration } \\
\text { direction in eastern Australia }\end{array}$} \\
\hline Sex & 5.44 & 0.039 & 0.039 & 0.001 \\
\hline Migration direction & 0.65 & 0.004 & 0.043 & 0.88 \\
\hline \multicolumn{5}{|c|}{$\begin{array}{l}\text { Analysis 2: the contribution of single } \\
\text { geographic groups to genetic divergence }\end{array}$} \\
\hline Colombia & 10.95 & 0.009 & 0.009 & 0.0 \\
\hline French Polynesia & 5.23 & 0.004 & 0.013 & 0.0 \\
\hline Western Australia & 2.45 & 0.002 & 0.015 & 0.0 \\
\hline Cook Islands & 1.81 & 0.001 & 0.016 & 0.05 \\
\hline Tonga & 1.86 & 0.002 & 0.018 & 0.02 \\
\hline New Caledonia & 0.27 & 0.000 & 0.018 & 1.0 \\
\hline Eastern Australia & 0.90 & 0.001 & 0.019 & 0.67 \\
\hline
\end{tabular}

in Olavarría et al. 2007 are included) sequence window, the 115 haplotypes described by Olavarría et al. (2007) collapsed into 109 distinguishable haplotypes, of which 37 (33.9\%) were found also in our eastern Australian sample (see Table 1). The merged data sets comprised 1247 whales and 114 unique haplotypes. Diversity indices for breeding grounds used for comparison are also shown in Table 2.

Fig. 1 shows the results of various pairwise tests for genetic differentiation $\left(\Phi_{\mathrm{ST}}\right)$ measured between migrants of the eastern Australia migratory corridor (EA) and whales wintering in adjacent breeding grounds. The null hypothesis could never be rejected when testing between EA samples and those from New Caledonia, both when samples were considered as a whole or as subclasses according to sex and/or migration (see Fig. 1). In general, our results indicate that the EA sample showed levels of genetic differentiation from the
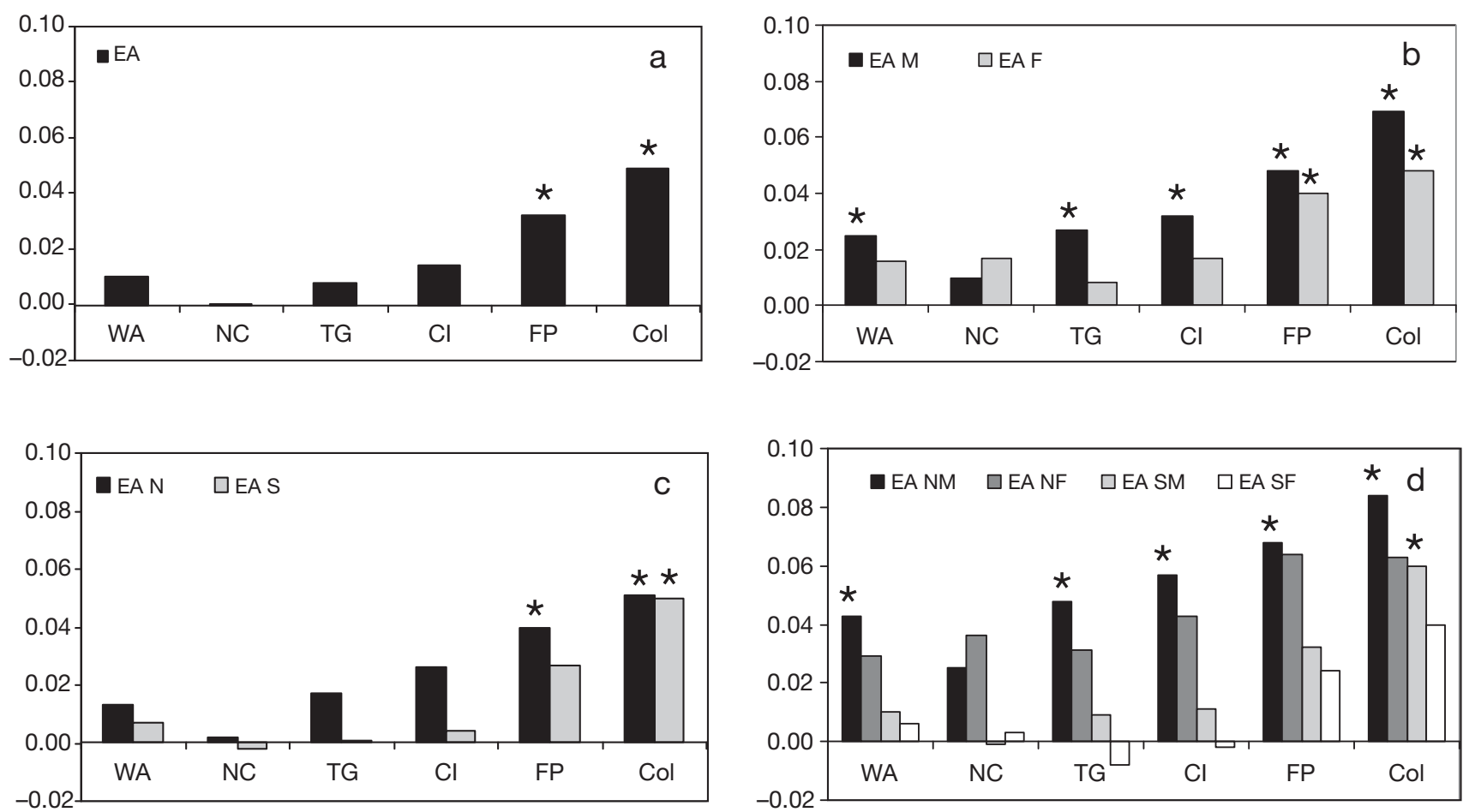

Fig. 1. Megaptera novaeangliae. Plots summarising the results of pairwise tests of genetic differentiation between mtDNA CR sequences sampled in eastern Australia (EA), western Australia (WA), New Caledonia (NC), Tonga (TG), Cook Island (CI), French Polynesia (FP) and Colombia (Col). Eastern Australian samples are compared to the others (described by Olavarría et al. 2007) in 4 different ways: (a) pulling all samples together, (b) keeping males and females separated, (c) separating northbound from southbound whales and (d) keeping males and females separated but also taking into account the migratory phase in which they were sampled. Stars highlight pairwise comparisons producing significant p-values ( $<<0.05)$ obtained in 10000 random permutations and corrected after adjustment for multiple comparison with the sequential Bonferroni correction test (Rice 1989) 
breeding grounds which increase eastwards with geographic distance, and low/intermediate levels of divergence with the western Australia population. Moreover, males in general (Fig. 1b) and those travelling north in particular (Fig. 1d) were the categories showing the highest levels of differentiation from other breeding sites. Conversely females, both in general (Fig. 1b) and those sampled either during the northern or the southern migrations (Fig. 1d), could not be differentiated from adjacent breeding regions (the female sample as a whole was distinguishable from the most remote French Polynesian and Colombian samples, Fig. 1b).

The relationship between genetic and geographic distances is supported by the GAMOVA analysis (Table 4, Analysis 2). The most genetically isolated group, i.e. the group explaining the highest proportion of variation, is the geographically remote sample from Colombia. Statistically significant proportions of explained variation were found also for the French Polynesia and western Australia samples. In general, decreases in pseudo- $F$ values (and therefore decreases in levels of isolation) were found moving westwards from Colombia to Australia.

\section{DISCUSSION}

This study is based on the first extensive genetic sample from a humpback whale migratory corridor, and represents the largest mitochondrial screening of whales sampled all from the same location throughout a single year's migration. Multiple comparisons within our sample show a highly significant differentiation $\left(\Phi_{\mathrm{ST}}=0.114, \mathrm{p}=0.001\right)$ between males and females migrating towards breeding waters. Given the received wisdom that humpback whales of both sexes migrate together, this anomalous observation deserves closer scrutiny. Moreover, the magnitude of the genetic difference is comparable to (or even greater than) those observed between adjacent breeding grounds (see Olavarría et al. 2007). This observation is even more remarkable considering that samples analysed from each particular location by Olavarría et al. (2007) were collected over periods ranging from 4 to $10 \mathrm{yr}$.

The genetic differentiation observed within our sample implies differences in the migratory behaviour of the 2 sexes. Such differences are not unknown in migratory marine megafauna (e.g. Le Boeuf et al. 2000). The seasonal migration undertaken by humpback whales is energetically costly. Whales may cover 1-way travel of up to $8000 \mathrm{~km}$ (Stone et al. 1990, Rasmussen et al. 2007). Furthermore, most of the travel, breeding and calving occurs in low productivity waters where prey resources are rare. An indirect indicator of the cost of migration is the predominance of males among migrating whales (e.g. Brown et al. 1995 found a sex ratio of males:females of 2.6:1 off eastern Australia). Females, which have costs of gestation and lactation added to migration, may opt for skipping migration in alternate years in order to recover from the energetic costs of reproduction (Brown et al. 1995). In this view it is not surprising females should select different routes than males, possibly in order to minimise the energetic cost of migration. Conversely, males should prefer itineraries which maximise reproductive opportunities.

Limitations of our sample present some difficulties in interpreting our data. The reproductive status of sampled individuals was unknown, but it may be that only reproductively mature individuals would be responsible for the gender-related differences in migration described above. For instance, sexually immature males (i.e. <6 yr old, see Chittleborough 1958, 1965, Clapham \& Mayo 1987, Clapham 1992) would probably still follow their mothers' routes, or they may not yet apply any migratory strategy to maximise their reproductive success. Secondly, little genetic information is currently available from putative Antarctic feeding grounds (Areas IV, V, and VI) which would provide informative data for our comparisons. Thirdly, if, as it appears, migration represents an opportunity for stock mixing, this would be true not just for our sample, but also for the adjacent breeding grounds used for comparison in this study and for which sex-specific information is currently lacking. These features inevitably contribute to poor resolution for determining the Antarctic origin of migrating whales. Nevertheless a few hypotheses can be evaluated in the light of our results, which clearly suggest the presence of a sex-specific migratory behaviour in eastern Australian humpback whales.

There are basically 2 possible routes for each migrating whale: either travelling along the $\mathrm{N}-\mathrm{S}$ axis (no longitudinal movement); or moving diagonally, eastward or westward (with longitudinal movement), before (or upon) reaching their migratory destination(s). We assume that (1) whales return to the same feeding ground from which they started their migration (site fidelity to feeding grounds), and (2) whales show sexspecific differences in their migratory routes. There are 4 possible scenarios hypothesised. These are summarized in Fig. 2 where, for simplicity, possible movements of whales from only 2 adjacent Antarctic feeding stocks are shown. The first 2 hypotheses (A and B) have the females as the gender that covers the shortest possible route (travelling perpendicular to the equator), while males would stretch their journeys to adjacent breeding grounds during either their northern (Hypothesis A) or their southern (Hypothesis B) migra- 

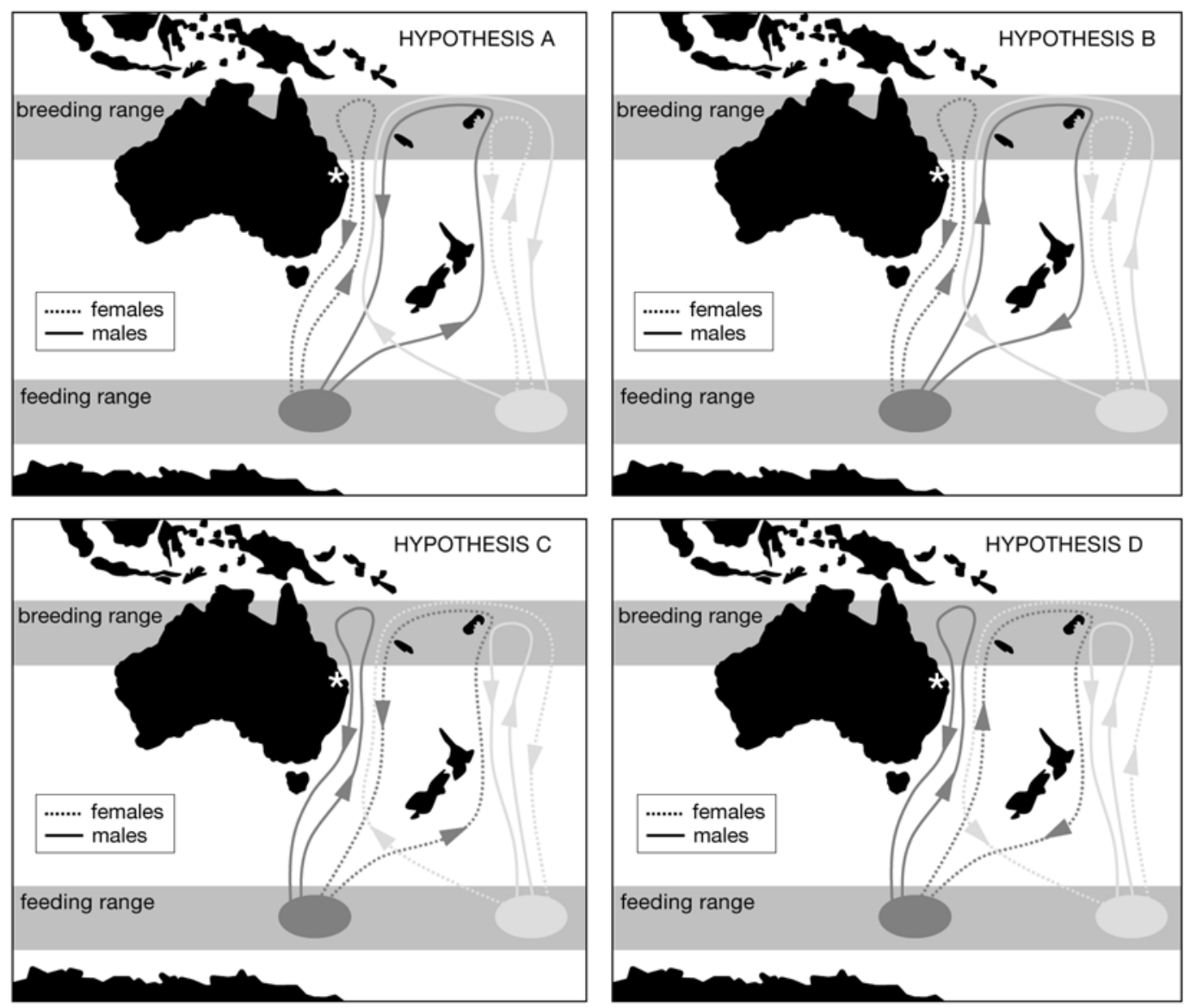

Fig. 2. Megaptera novaeangliae. Simplified representation of possible sex-specific migratory movements across adjacent feeding grounds. For clarity only 2 hypothetical feeding areas are shown. The white star indicates the latitude of the sampling site

tions. In the 2 remaining hypotheses $(C$ and $D)$ the degree of female / male mobility would be reversed.

For each hypothesis an expected combination of binary scores (similar or different) in pairwise comparisons between sample classes could be determined and compared with the observed outcomes (Tables 3 \& 5). In this comparison between different hypotheses, we assume that 3 pairwise $\Phi_{\mathrm{ST}}$ values in the real data support genetic divergence, and 3 of them do not. This assumption, even if only one $\Phi_{\mathrm{ST}}$ value was significant after sequential Bonferroni correction for multiple tests, appears justified since (1) the hypothesis-testing framework we are using here is exploratory; (2) $3 \Phi_{\mathrm{ST}}$ values are larger than $5 \%$, and 3 are smaller than $1 \%$; (3) all $\Phi_{\mathrm{ST}}$ values larger than $5 \%$ have p-values (before correction) smaller than 0.02, and Bonferroni corrections are generally believed to be over-conservative (e.g. Altman 1991, Verhoeven et al. 2005).

Table 5. Expected scores of similarity $(=)$ and differentiation $(\neq)$ between the 4 sex/migration classes according to each of the 4 hypotheses (A, B, C and D; see Fig. 2) are compared to the observed scores ('<>' for $\Phi_{\mathrm{ST}}<0.01 ;{ }^{\prime} \neq^{\prime}$ ' for $\Phi_{\mathrm{ST}}>0.01$ ). The fractions at the bottom of the table summarize how many of the 6 expected scores matched the observed ones

\begin{tabular}{|c|c|c|c|c|c|}
\hline Comparisons & Hypothesis A & Hypothesis B & Hypothesis C & Hypothesis D & Observed \\
\hline NM-NF & $\neq$ & $=$ & $\neq$ & $=$ & $\neq$ \\
\hline SM-SF & $=$ & $\neq$ & $=$ & $\neq$ & $<>$ \\
\hline NM-SF & $\neq$ & $=$ & $=$ & $\neq$ & $\neq$ \\
\hline SM-NF & $=$ & $\neq$ & $\neq$ & $=$ & $\neq$ \\
\hline NM-SM & $\neq$ & $\neq$ & $=$ & $=$ & $<>$ \\
\hline \multirow[t]{2}{*}{ NF-SF } & $=$ & $=$ & $\neq$ & $\neq$ & $<>$ \\
\hline & $4 / 6$ & $2 / 6$ & $4 / 6$ & $2 / 6$ & \\
\hline
\end{tabular}


According to our findings, the best supported hypotheses of this set are A and C: 4 of the 6 expected scores for pairwise comparisons are observed in our results. However, behavioural evidence seems to support Hypothesis A: all but 1 (of unidentified gender) of the 7 whales photographically identified at least twice by Garrigue et al. (2007b), once in the insular breeding habitats of the southwest Pacific and once in eastern Australia, were males. Moreover, the only 2 encounters of the same individual within the same year between the New Zealand and the eastern Australian migratory corridors (Garrigue et al. 2007b, Table 3) involved adult males sampled first in New Zealand and later in the season (southern migration) off eastern Australia. Finally, the ecological reasons why it would seem unlikely that females might undertake longer migrations than male (as implied in Hypothesis C) have been mentioned above. In all, while accepting that the data do not allow full resolution, we suggest that on the evidence available, Hypothesis A (males making greater longitudinal movements, and males of the 'Australian' population moving northward elsewhere in the western South Pacific) seems the most probable of these 4 options.

Although both patterns of sex-specific genetic differentiation and behavioural data provide the strongest support for Hypothesis A, an apparently anomalous issue is that if females are the least mobile part of the migrating population, how can they show no significant differentiation from most southwest Pacific breeding sites (Fig. 1b,d)? In answering this, we must bear in mind the lack of homogeneity in the samples used here for comparisons: in all breeding sites for which genetic data were available, males and females were pooled together.

Thus, comparing EA females to whales sampled elsewhere in the South Pacific means comparing them to both females and males wintering in those sites; our data suggest some, particularly males, might come from different populations. In other words, observing low differentiation between EA females and adjacent breeding sites might not indicate the capability of females to cover long distances stretching their routes up to those localities, but rather the presence in those sites of their male relatives. Although our data suggest that comparisons between genetic data aggregated by gender may be spurious, we have included these analyses here as they provide comparisons with previous data from the South Pacific; they further highlight genetic differences in our data based on gender and migratory direction, and they give us some clues on where the differences lay (e.g. southbound whales are more similar in composition to those found on adjacent breeding grounds than northbound whales; Fig. 1c,d).
Two comparisons within our samples were not in accord with Hypothesis A: that northern males should be different from southern males (we were not able to reject the null of no difference), and that southern males should be the same as northern females (this hypothesis was rejected).

Firstly however, as mentioned above, migrating whales include all maturational classes. Assuming that males and females follow alternative routes to increase reproductive success, such behaviour would be shown only by sexually mature individuals, while youngsters are likely to follow the route of their mother. Thus, in the case of differentiating between northern and southern males, we would expect sexually immature males to move along the $\mathrm{N}-\mathrm{S}$ axis as do females; therefore the northbound males' sample would include immature males following their female relatives as well as mature males from adjacent feeding grounds.

Secondly, our sampling site is close to breeding waters and whales were still engaged in breeding behaviour (Brown \& Corkeron 1995). It may be that not all whales had started on their definitive routes back to their feeding grounds at the time of sampling, especially at the beginning of the southern migration (second half of August/beginning of September). Such a scenario might also find support in what Clapham \& Zerbini (2006) propose as the 'Social Attraction Hypothesis', a possible explanation for the rapid growth of some populations of humpback whale in which they use the population migrating off the coast of eastern Australia as a specific example. They suggest the rapid eastern Australia population increase might be due to its relatively large size in comparison with neighbouring populations, so attracting whales from other populations to join those migrating off eastern Australia. This could explain both our inability to detect a difference between northbound and southbound males, and the difference between southbound males and northern females: the relatively large pool of potential mates off eastern Australia attracts males from other areas.

Whatever the trajectory favoured by either sex, it does not mean that the same pattern of sex-specific behaviour we found evidence for in eastern Australia must apply to adjacent breeding grounds; the eastern Australian migratory corridor may be an area where sex-specific migratory behaviours leading to mixing between adjacent stocks is more likely to occur. This could be due to geography (as discussed in the Introduction), or a result of exploitation of humpback whales in the region during the mid-20th century, as per the Social Attraction Hypothesis.

Whatever the reason, if mixing from adjacent stocks was occurring, we would expect molecular diversity to be high within our sample. The eastern Australian 
sample recorded the highest nucleotide diversity value ( $\pi=2.61 \%$ ) among those observed in whales from adjacent regions (see Table 2), while the level of haplotype diversity $(\mathrm{H}=0.968)$ was not dissimilar from that observed in western Australia, New Caledonia and Tonga.

This suggests that, although the relative number of different haplotypes is roughly the same throughout the area, in eastern Australia we can find a larger variety of molecularly distant haplotypes. Interestingly, among the various eastern Australia subsamples, the highest divergence between haplotypes was recorded during the northern migration $(\pi=2.74 \%)$, with values which fell back in the population average once northbound males and females were treated separately $(\pi=$ 2.61 and $2.60 \%$ respectively), confirming the diverse origin of northbound male and female migrants.

In conclusion, we find evidence in our sample for sex-specific migratory behaviour in humpback whales off eastern Australia. Although the genetic and behavioural evidence does not allow us to distinguish definitively the patterns involved in humpback whale migratory behaviour, our data suggest that males may cover longer distances than females, presumably in order to maximise reproductive opportunities. Movements of females are more likely to be constrained by the energetics of reproduction. Moreover, such behavioural difference may be a means by which whale stocks intermix. Indeed, the correlation between genetic and geographic distances (Fig. 1) lets us presume a certain degree of mixing over short distances between directly adjacent breeding sites.

Exchanges of individuals between breeding grounds may not be rare in this part of the Southern Ocean now, contrary to the suggestion of Garrigue et al. $(2004,2007 a, b)$ that humpback whales wintering off New Caledonia form an isolated population. All eastern Australian subsamples showed no significant genetic differentiation from the New Caledonian wintering population, and all of the 17 most frequent ( $\mathrm{n}>$ 4) haplotypes were also found in New Caledonia by Olavarría et al. (2007). This lack of differentiation appears particularly the case during the southward migration (Fig. 1d). In all, our results support and extend the view of Palsbøll et al. (2005) regarding the possibility of eastern Australian males mating with New Caledonian females.

Where do the males migrating northwards along the eastern Australian migratory corridor come from? A key assumption of our hypotheses is that genetically discrete populations of whales migrate back to separate Antarctic feeding ranges (Fig. 2). This may be incorrect. A fifth possible hypothesis is that the males migrating north and south off the eastern Australian coastline in 1992 came from a completely separate
Antarctic feeding 'population' than the females; in a comparison such as those shown in Fig. 2, this appears to fit the data better than Hypothesis A, with 5 of 6 pairwise comparisons showing agreement with this hypothesis. However, this begs the question of where in Antarctic waters those males may come from and, reciprocally, where do the 'eastern Australian' males (i.e. those summering in the Antarctic waters underneath eastern Australia) go? It also fails to explain the differences in levels of genetic differentiation between northern and southern migrating males (which would supposedly be the same according to this new hypothesis) and animals sampled off New Caledonia (Fig. 1d). Our data suggest that longitudinal movements by males in tropical and through migratory latitudes are more extensive than currently believed.

Our findings imply a complete re-examination of genetic data from humpback whales in the South Pacific. In order to clarify the sex-specific population dynamics characterising humpback whale stock differentiation in the Southern Ocean, we recommend that female and male humpback whales (and perhaps baleen whales generally) should be tested for genetic homogeneity in future studies and, if appropriate, should be treated separately. However, the most conclusive contribution to the identification of sex-specific migratory routes in the Southern Ocean humpback whale would come from: (1) comparison of currently available data from Antarctic samples from the International Whaling Commission management Areas IV, V, VI and I in the Southern Hemisphere; (2) sampling elsewhere on the migratory paths identified (e.g. Norfolk Island); and (3) repeating the 1992 study off southern Queensland.

Finally, a prosaic but cautionary note: land-based estimates of the abundance of humpback whales migrating past Point Lookout, Queensland (Australia) are thought to represent the IWC's 'breeding population E1', which is presumed to be linked to the IWC's Antarctic Area V population (e.g. Paterson et al. 2004). Our data suggest that the real situation is far more complex.

Acknowledgements. We are very grateful to N. Boero and 3 anonymous reviewers for valuable comments on the manuscript and to M. Brown for organising and supervising sample collection. We thank K. Schultz and the many volunteers who assisted with sample collection. We also thank: IDP-Australia (AEAP Fellowship), the University of New South Wales (UNSW Vice-Chancellor Research Fellowship), Environment Australia (Grant \#RSP_MS96-01 to PH), the Sea World Research and Rescue Foundation Inc. and the Dept. of Veterinary Anatomy and Pathology, The University of Sydney for financial support. Sampling was carried out under permits from the Queensland Fish Management Authority and with ethical approval from the University of Sydney. 


\section{LITERATURE CITED}

Altman DG (1991) Practical statistics for medical research. Chapman \& Hall, London

Baker CS, Perry A, Bannister JL, Weinrich MT and others (1993) Abundant mitochondrial-DNA variation and worldwide population structure in humpback whales. Proc Natl Acad Sci USA 90:8239-8243

Baker CS, Flórez-González L, Abernethy B, Rosenbaum HC, Slade RW, Capella J, Bannister JL (1998) Mitochondrial DNA variation and maternal gene flow among humpback whales of the Southern Hemisphere (Megaptera novaeangliae). Mar Mamm Sci 14:721-737

Baker CS, Garrigue C, Dodemont R, Steel D (2005) Statistical power and plausible alternate hypotheses of gametic recapture estimates from wintering grounds of humpback whales. Mar Ecol Prog Ser 295:309-311

Brown M, Corkeron P (1995) Pod characteristics of migrating humpback whales (Megaptera novaeangliae) off the East Australian coast. Behaviour 132:163-179

Brown M, Corkeron P, Hale P, Schultz K, Bryden M (1995) Evidence for a sex-segregated migration in the humpback whale (Megaptera novaeangliae). Proc R Soc Lond B Biol Sci 259:229-234

Campbell NJH, Harriss FC, Elphinstone MS, Baverstock PR (1995) Outgroup heteroduplex analysis using temperature gradient gel electrophoresis: high resolution, large scale, screening of DNA variation in the mitochondrial control region. Mol Ecol 4:407-418

Chittleborough RG (1958) The breeding cycle of the female humpback whale, Megaptera nodosa (Bonnaterre). Aust J Mar Freshwater Res 9:1-18

Chittleborough RG (1961) Australian catches of humpback whales 1960. Norsk Hvalfangst-Tidende 50:452-483

> Chittleborough RG (1965) Dynamics of two populations of humpback whale, Megaptera novaeangliae (Borowski). Aust J Mar Freshwater Res 16:33-128

Clapham PJ (1992) Age at attainment of sexual maturity in humpback whales, Megaptera novaeangliae. Can J Zool 70:1470-1472

Clapham PJ (2000) The humpback whale: seasonal feeding and breeding in a baleen whale. In: Mann J, Connor RC, Tyack PL, Whitehead H (eds) Cetacean societies: field studies of dolphins and whales. University of Chicago Press, Chicago, p 173-196

$>$ Clapham PJ, Mayo CA (1987) Reproduction and recruitment of individually-identified humpback whales, Megaptera novaeangliae, observed in Massachusetts Bay, 1979-1985. Can J Zool 65:2853-2863

Clapham PJ, Mead JG (1999) Megaptera novaeangliae. Mamm Species 604:1-9

Clapham PJ, Zerbini A (2006) Is social aggregation driving high rates of increase in some Southern Hemisphere humpback whale populations? Paper IWC/58/SH3 presented at the 58th Meeting of the Scientific Committee of the International Whaling Commission, St. Kitts and Nevi, (available from the International Whaling Commission, Cambridge)

Craig AS, Herman LM (1997) Sex differences in site fidelity and migration of humpback whale (Megaptera novaeangliae) to the Hawaiian Islands. Can J Zool 75:1923-1933

Craig AS, Herman LM, Gabriele CM, Pack AA (2003) Migratory timing of humpback whales (Megaptera novaeangliae) in the central North Pacific varies with age, sex and reproductive status. Behaviour 140:981-1001

Dawbin W (1966) The seasonal migratory cycle of the humpback whale. In: Norris K (ed) Whales, dolphins and por- poises. University of California Press, Berkeley, p 145-170

- Excoffier L, Smouse P, Quattro J (1992) Analysis of molecular variance inferred from metric distances among DNA haplotypes: application to human mitochondrial DNA restriction data. Genetics 131:479-491

Excoffier L, Laval G, Schneider S (2005) Arlequin ver. 3.0: an integrated software package for population genetics data analysis. Evol Bioinform Online 1:47-50

Ford JKB, Reeves RR (2008) Fight or flight: antipredator strategies of baleen whales. Mammal Rev 38:50-86

Franklin W, Franklin T, Brooks L, Gibbs N and others (2008) Eastern Australia (E1 breeding grounds) may be a wintering destination for Area V Humpback Whales (Megaptera novaeangliae) migrating through New Zealand waters. Paper SC/60/SH3 presented to the IWC Scientific Committee, June 2008, Santiago, Chile (available from the International Whaling Commission, Cambridge)

Garrigue C, Forestell P, Greaves J, Gill P, Naessig P, Patenaude NM, Baker CS (2000) Migratory movements of humpback whales (Megaptera novaeangliae) between New Caledonia, East Australia and New Zealand. J Cetacean Res Manag 2:111-115

> Garrigue C, Dodemont R, Steel D, Baker CS (2004) Organismal and 'gametic' capture-recapture using microsatellite genotyping confirm low abundance and reproductive autonomy of humpback whales on the wintering grounds of New Caledonia. Mar Ecol Prog Ser 274:251-262

Garrigue C, Baker CS, Constantine R, Poole M and others (2007a) Interchange of humpback whales in Oceania (South Pacific) 1999-2004. (revised SC/A06/HW55, March 2007). Paper SC/59/SH14 presented to the IWC Scientific Committee, May 2007, Anchorage, Alaska (available from the International Whaling Commission, Cambridge)

Garrigue C, Franklin T, Russell K, Burns D and others (2007b) First assessment of interchange of humpback whales between Oceania and the east coast of Australia. Paper SC/59/SH15 presented to the IWC Scientific Committee, May 2007, Anchorage, Alaska (available from the International Whaling Commission, Cambridge)

Gibson Q, Kaufman G, Forestell P (2009) Status report: Photoidentification of humpback whales at multiple aggregation areas along east coast Australia. Paper SC/61/SH25 presented to the IWC Scientific Committee, June 2009, Madeira, Portugal (available from the International Whaling Commission, Cambridge)

Jann B, Allen J, Carrillo M, Hanquet S and others (2003) Migration of a humpback whale (Megaptera novaeangliae) between the Cape Verde Islands and Iceland. J Cetacean Res Manag 5:125-129

Larsen AH, Sigurjonsson J, Øien N, Vikingsson G, Palsbøll PJ (1996) Populations genetic analysis of nuclear and mitochondrial loci in skin biopsies collected from central northeastern North Atlantic humpback whales (Megaptera novaeangliae): population identity and migratory destinations. Proc R Soc Lond B Biol Sci 263:1611-1618

> Le Boeuf BJ, Crocker DE, Costa DP, Blackwell SB, Webb PM, Houser DS (2000) Foraging ecology of Northern Elephant Seals. Ecol Monogr 70:353-382

Mehta AV, Allen JM, Constantine R, Garrigue C and others (2007) Baleen whales are not important as prey for killer whales (Orcinus orca) in high latitudes. Mar Ecol Prog Ser 348:297-307

Nei M (1987) Molecular evolutionary genetics. Columbia University Press, New York

> Nievergelt CM, Libiger O, Schork NJ (2007) Generalized analysis of molecular variance. PLoS Genet 3:e51

Noad MJ, Cato DH, Bryden MM, Jenner MN, Jenner KCS 
(2000) Cultural revolution in whale songs. Nature 408:537

Olavarría C, Baker CS, Garrigue C, Poole M and others (2007) Population structure of South Pacific humpback whales and the origin of the eastern Polynesian breeding grounds. Mar Ecol Prog Ser 330:257-268

Palsbøll PJ, Berube M, Anderson EC, Dunham KK (2005) High levels of statistical uncertainty in 'gametic' recapture estimates of male abundance in humpback whales. Mar Ecol Prog Ser 295:305-307

Paterson RA, Paterson P, Cato DH (2001) Status of humpback whales, Megaptera novaeangliae, in east Australia at the end of the 20th century. Mem Queensl Mus 47:579-586

Paterson R, Paterson P, Cato DH (2004) Continued increase in East Australian humpback whales in 2001, 2002. Mem Queensl Mus 49:712

Pomilla C, Rosenbaum HC (2006) Estimates of relatedness in groups of humpback whales (Megaptera novaeangliae) on 2 wintering grounds of the Southern Hemisphere. Mol Ecol 15:2541-2555

Rasmussen K, Palacios DM, Calambokidis J, Saborio MT and

Editorial responsibility: Hans Heinrich Janssen,

Oldendorf/Luhe, Germany others (2007) Southern Hemisphere humpback whales wintering off Central America: insights from water temperature into the longest mammalian migration. Biol Lett 3:302-305

Rendell L, Whitehead H (2001) Culture in whales and dolphins. Behav Brain Sci 24:309-382

Rice WR (1989) Analyzing tables of statistical test. Evolution 43:223-225

Stevick PT, Allen J, Berube M, Clapham PJ and others (2003) Segregation of migration by feeding ground origin in North Atlantic humpback whales (Megaptera novaeangliae). J Zool (Lond) 259:231-237

Stone GS, Florez-Gonzalez L, Katona S (1990) Whale migration record. Nature 346:705

Valsecchi E, Hale P, Corkeron P, Amos W (2002) Social structure in migrating humpback whales (Megaptera novaeangliae). Mol Ecol 11:507-518

- Verhoeven KJF, Simonsen KL, McIntyre LM (2005) Implementing false discovery rate control: increasing your power. Oikos 108:643-647

Submitted: November 13, 2008; Accepted: August 24, 2009

Proofs received from author(s): December 1, 2009 